\section{Edycasace

ARTIGO

\section{Editor}

Alexandre Anselmo Guilherme PUCRS, RS, Brasil

\section{Editor Assistente}

\section{Cibele Cheron}

PUCRS, RS, Brasil

\section{Editores Associados}

Bruno Antonio Picoli

Universidade Federal da Fronteira Sul, Chapecó, SC, Brasil

Pricila Kohls dos Santos Universidade Católica de Brasília, Brasília, DF, Brasil

Renato de Oliveira Brito

Universidade Católica de Brasilia, Brasilia, DF, Brasil

Elisa Ustarroz

PUCRS, Porto Alegre, RS, Brasil

\section{ISSN 2179-8435}

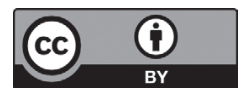

Este artigo está licenciado sob forma de uma licença Creative Commons Atribuição 4.0 Internacional, que permite uso irrestrito, distribuicăo e reprodução seja corretamente citada

\title{
Projetos de Aprendizagem na Perspectiva do Hibridismo e da Multimodalidade no Contexto da Pedagogia Parfor: engajar para Aprender
}

\author{
Learning Projects in the Perspective of Hybridism and Multimodality \\ in the Context of Pedagogy Parfor: engage to Learn
}

Ederson Luiz Locatelli $\odot$

Universidade do Vale do Rio dos Sinos, São Leopoldo, RS, Brasil.

\section{RESUMO}

É comum, quando ministro atividades acadêmicas que abordam as tecnologias digitais, que as alunas inicialmente tragam no discurso: "isto não dá pra fazer", "na escola não tem equipamento", "o laboratório não pode ser usado" etc. Isso evidencia que, muitas vezes, há uma resistência em repensar práticas e adotar novas formas de ensinar, considerando o sujeito da aprendizagem que está na sala de aula. O problema de pesquisa deste artigo é compreender de que forma as alunas do curso de Pedagogia do Plano Nacional de Formação dos Professores da Educação Básica (Parfor) em convênio com a Universidade do Vale do Rio dos Sinos (Unisinos) se apropriam das tecnologias digitais por meio do engajamento e do desenvolvimento de projetos de aprendizagem na perspectiva do hibridismo e da multimodalidade proporcionando a reinvenção da sua prática docente? Para responder tal questão, a metodologia configura-se como qualitativa, de natureza aplicada e realizará uma análise textual discursiva (MORAES, 2003) das produções das alunas nas atividades realizadas ao longo do semestre. Como principais resultados, os dados evidenciaram uma boa compreensão e um forte engajamento das alunas no que se refere à metodologia de projetos de aprendizagem e, com isso, a superação da resistência em relação às tecnologias digitais inovando nas práticas pedagógicas, considerando o hibridismo e a multimodalidade.

Palavras-chave: Parfor. Pedagogia. Projetos de aprendizagem. Hibridismo. Multimodalidade.

\section{ABSTRACT}

It is common, when I teach academic activities that approach the digital technologies, that the students initially bring in the speech: "this can not do", "at school does not have equipment", "the lab can not be used", etc. This shows that there is often a resistance to rethinking their practices and adopting new ways of teaching, considering the students who are into the classroom. The research problem is to understand how PARFOR Pedagogy students take ownership of digital technologies through the engagement and development of learning projects from the 
perspective of hybridism and multimodality, providing the reinvention of their teaching practice? In order to answer such question, the methodology is configured as qualitative, of an applied nature and will perform a discursive textual analysis (MORAES, 2003) of the productions of the students in the activities carried out during the semester. As the main results, the data showed a good understanding and a strong commitment of the students in the methodology of learning projects and, with this, the overcoming of the resistance in relation to the digital technologies innovating in the pedagogical practices considering hybridity and multimodality.

Keywords: Parfor. Pedagogy. Learning projects. Hybridism. Multimodality.

\section{Introdução}

- az parte do nosso cotidiano o uso de dispositivos tecnológicos, os quais permitem executar diversas ações, sejam

$\mathrm{F}$ elas na dimensão pessoal, na acadêmica ou na profissional. Essas ações têm sofrido profundas alterações e têm sido potencializadas pelas tecnologias considerando a conectividade estabelecida, transgredindo a limitação geográfica e mudando nossa forma de ser e estar no mundo. Contudo, a escola muitas vezes parece estar fora desse contexto, pois não se abre para repensar suas práticas, adotando novas formas de ensinar, que conside o sujeito da aprendizagem que está na sala de aula. Isso é evidenciado em certas falas das alunas da Pedagogia Parfor ${ }^{1}$ Unisinos tais como: "isto não dá pra fazer", "na escola não tem equipamento", "o laboratório não pode ser usado" etc. Cabe ressaltar que estas alunas atuam em escolas públicas nas diferentes cidades da região. Entretanto, ao longo do semestre, o do estudo de conceitos que problematizam e fundamentam a educação na cultura digital e o desenvolvimento de projetos de aprendizagem (FAGUNDES; SATO; MAÇADA, 1999) possibilitam a reflexão e a prática pedagógica no contexto do hibridismo e da multimodalidade. Por isso, o problema de pesquisa deste trabalho é compreender de que forma as alunas do curso de Pedagogia Parflor se apropriam das tecnologias digitais por meio do engajamento e do desenvolvimento de projetos de aprendizagem na perspectiva do hibridismo e da multimodalidade, proporcionando a reinvenção da sua prática docente? O estudo realizado teve como cenário tanto a atividade acadêmica na universidade quanto o contexto da escola em que as professora-alunas estavam inseridas como docentes em diferentes níveis: no berçário, nas Séries Iniciais, na Educação Infantil e no Ensino Fundamental.

\footnotetext{
1 Programa Nacional de Formação de Professores da Educação Básica (Parflor). Disponível em: http://www.capes.gov.br/educacao-basica/ parfor. Acesso em: 30 jul. 2018.
} 


\section{Outras redes, novos atores: projetos de aprendizagem no contexto do hibridismo e da multimodalidade}

Com o passar dos tempos, no contexto contemporâneo a evolução do conceito de técnica e o conceito tecnologia nos fazem pensar no potencial criativo do ser humano, o qual se coloca como atividade na própria construção do ser e estar no mundo tanto no âmbito social, quanto na sua relação com o mundo. Segundo sociólogo Di Felice (2012, p. 16),

Não podemos mais pensar as mídias como "ferramentas", instrumentos a serem utilizados, pois, ao utilizarmos novos meios, passamos a desenvolver novos tipos de interação e experimentamos novas formas de interação social. Desde as redes sociais digitais (social network) aos celulares, as tecnologias midiáticas são portadoras de inovação não apenas no âmbito tecnológico, comunicativo e sensorial, mas também no âmbito mais amplo do social, alcançando seus diversos níveis, político, econômico, organizativo, cultural, etc.

Na sua concepção, a inovação tem feito parte do contexto em que vivemos, mas ela só é possível quando tecnológico e social se imbricam. É nesse sentido que trago o conceito de cibercultura que, segundo Lemos (2004, p. 105) caracteriza-se sob três elementos:

a) a liberação do polo de emissão: todo sujeito pode ser autor e compartilhar na rede suas produções;

b) a conexão generalizada: todos estão conectados a todo o tempo;

c) a econfiguração: essas transformações devem proporcionar a reformulação das nossas ações no mundo.

Para Lemos (2004, p. 105), a cibercultura, com a microinformática, torna-se mais que o desenvolvimento linear da lógica cibernética, surgindo como uma espécie de movimento social, pois a microinformática vai acentuar a democratização do acesso à informação e, com isso, os sujeitos tornam-se atores atuantes na tessitura da web. É esse acesso que tem possibilitado, segundo Di Felice (2012, p.13), "uma nova cultura tecnológica e comunicativa que marca o cotidiano e a existência das novas gerações que vivem em contextos sociais e midiáticos digitais, e que produzem alterações qualitativas na política, na democracia e na forma de pensar a sociedade".

É nessa nova cultura tecnológica e comunicativa que Di Felice (2012a, p. 10) diz que "somos atores de um ecossistema do qual fazemos parte como participantes e não apenas como observadores externos e independentes". É nessa ação do sujeito participante que o autor afirma o surgimento da cultura ecossistêmica, ou seja, 
O social reticular é expressão de uma cultura ecossistêmica nos contextos digitais dos processos comunicativos e que caracteriza as formas de uma inteligência relacional, sem centro e distribuída em todos os lugares. A ação e o conhecimento do sujeito se tornam assim relacionados e não mais autocentrados, resultado de uma qualidade conectiva que manifesta a passagem da comunicação com o ambiente à comunicação no ambiente (DI FELICE, 2012, p. 18).

Além disso, o imbricamento da ação do sujeito no ambiente nos remete a Latour (2016) e o seu conceito de hibridismo, o qual significa enquanto constituído por múltiplas matrizes, por misturas de natureza e cultura e, ou seja, não transporta causalidade e não há hierarquizações. Mas como pensar o conceito de hibridismo no contexto das práticas pedagógicas e o engajamento das professoras-alunas? Segundo Schlemmer (2015, p.408),

Híbridas são as ações e interações entre atores humanos e não humanos, em espaços e culturas analógicas e digitais, constituindo-se em fenômenos indissociáveis, redes que interligam naturezas, técnicas e culturas. Para o autor, enquanto não superarmos a distinção cultura/natureza, humano/não humano, ou seja, enquanto mantivermos a distinção ontológica, nossas atividades serão uma contínua construção de problemas e situações interpretadas como possuindo natureza científica, política, social, econômica, ideológica etc., ou seja, uma visão de mundo compartimentada, dicotômica e excludente.

Nesse contexto de interação entre atores humanos e não humanos e, principalmente culturas analógicas e digitais que novas configurações e possibilidades de práticas pedagógicas surgem proporcionando inovação, pois, segundo Schlemmer e Backes (2013, p. 245),

pensar a Educação na contemporaneidade implica considerar que os processos de ensinar e de aprender ocorrem na coexistência entre os espaços geográficos e os espaços digitais virtuais e, em compreender que as rápidas mudanças se dão dialeticamente entre educação e TD, pois ao mesmo tempo que as TD provocam transformações no contexto da educação, elas provocam a criação de novas TD.

Essa coexistência entre os espaços geográficos e os espaços digitais virtuais as professoras-alunas foram experienciando ao longo da atividade acadêmica. Ao mesmo tempo em que estudavam na modalidade a distância, desenvolviam os projetos de aprendizagem presencialmente, no contexto da educação básica em que atuavam como professora, vivenciando assim a multimodalidade, ou seja, modalidade presencial-física configurando-se (face-toface), e a modalidade online, que inclui: eletronic learning (e-learning), mobile learning (m-learning), pervasive 
learning (p-learning), ubiquitous learning (u-learning), immersive learning (i-learning), gamification learning (g-learning), game based learning (GBL). (SCHLEMMER, 2015, p.408). Essa vivência proporcionou, segundo Schlemmer (2015), repensar novo contexto, dentre eles espaço, presença, tecnologias e culturas. Com isso, a educação potencializa as possibilidades de desenvolver práticas pedagógicas considerando os sujeitos deste tempo histórico e social, engajando-os em projetos que proporcionem aprendizagem.

Com base nesses conceitos e no contexto entendido como híbrido e multimodal é que a seguir será descrita a experiência realizada no curso de Graduação em Pedagogia Parflor da Unisinos, na atividade acadêmica "Ensinar e Aprender no Mundo Digital".

\section{Delineamento metodológico}

Para Minayo (2007, p. 14, grifo do autor), a metodologia é o caminho do pensamento e a prática exercida na abordagem da realidade. Seguindo esse raciocínio, o pesquisador torna-se um sujeito atento à realidade, na qual busca cada vez mais fundamentos para sustentar o seu posicionamento em relação a ela mesma.

Com o intuito de ir clarificando o percurso a ser adotado, do ponto de vista da abordagem, a pesquisa se configura como qualitativa, pois trabalha mais com a subjetividade, é flexível, é processual, descobre, produz os dados, contrapondo-se à abordagem quantitativa. Para Silva e Menezes (2001, p. 20), a abordagem qualitativa:

[...] considera que há uma relação dinâmica entre o mundo real e o sujeito, isto é, um vínculo indissociável entre o mundo objetivo e a subjetividade do sujeito que não pode ser traduzido em números. A interpretação dos fenômenos e a atribuição de significados são básicas no processo de pesquisa qualitativa.

Sob esses fundamentos, buscando contextualizar esta pesquisa quanto ao seu delineamento, podemos dizer que ela é de natureza aplicada, pois o conhecimento gerado visa a aprimorar o trabalho no que se refere ao desenvolvimento de projetos de aprendizagem híbrido e multimodal no contexto da Pedagogia Parfor.

Para realizar a análise qualitativa dos dados, adotei a metodologia chamada por Moraes (2003) de Tempestade de Luz $^{2}$, que compreende basicamente quatro etapas: 1) a desmontagem do texto; 2) o estabelecimento de relações; 3) a captação do novo emergente; e 4) um processo auto-organizado.

2 O autor dá o nome Tempestade de luz à análise textual discursiva, conforme apresentado nas considerações finais do artigo "Uma tempestade de luz: a compreensão possibilitada pela análise textual discursiva" (MORAES, 2003). 
A metodologia proposta por Moraes (2003) consiste em apresentar a análise textual discursiva, contextualizada na pesquisa qualitativa.

Apresentando-a como uma tempestade de luz, metodologia que se afastando do que tradicionalmente tem sido denominado de análise de conteúdo, aproximando-se de algumas modalidades de análise de discurso, procuramos argumentar que essa abordagem de análise pode ser concebida como um processo auto-organizado de produção de novas compreensões em relação aos fenômenos que examina (MORAES, 2003, p. 19).

Segundo Moraes (2003), “esta metodologia não pretende testar hipóteses para comprová-las ou refutá-las ao final da pesquisa; a intenção é a compreensão".

\section{Contexto da Pesquisa}

A atividade acadêmica foi desenvolvida na modalidade a distância considerando o semestre com 19 semanas, no qual cinco encontros foram presenciais-físicos e os demais presenciais-virtuais, utilizando o Moodle-Unisinos e outras tecnologias de interação a distância (Second Life, Google Hangout e outros). Os encontros presenciais-físicos foram destinados prioritariamente para orientações e apresentação da atividade acadêmica, exploração de softwares, soluções de dúvidas, avaliações e discussões sobre os conhecimentos construídos.

O foco dessa atividade acadêmica, intitulada "Programa de Aprendizagem Ensino e Aprendizagem no Mundo Digital" foi criar espaços de aprendizagem e de emancipação digital que desenvolvam postura teórico-metodológica e conhecimento tecnológico que favoreçam a integração de diferentes tecnologias digitais virtuais - TDVs na construção do conhecimento. Buscou a reflexão sobre a apropriação dessas tecnologias para o desenvolvimento humano e social no âmbito da Educação Infantil, dos Anos Iniciais e da Educação de Jovens e Adultos. Para isto, ao longo do semestre, as alunas desenvolveram Projetos de Aprendizagem procurando integrar os conhecimentos construídos em aula com o contexto da escola no qual estão atuando.

Essa atividade acadêmica teve como objetivos:

a) utilizar as Tecnologias Digitais Virtuais - TDVs na educação numa visão crítica e humanística;

b) decidir quanto à escolha e uso das TDVs em sua prática pedagógica, identificando os pressupostos epistemológicos implícitos no desenvolvimento dos projetos e softwares;

c) reconhecer o paradigma educacional que norteia uma prática pedagógica com o uso dos TDVs; 
d) criar um ambiente de aprendizagem desafiador que promova o desenvolvimento da autonomia, a interação e a cooperação num processo de construção do conhecimento, favorecido pela pesquisa na busca de inovação educacional;

e) estabelecer relações entre a teoria, a vivência enquanto aluno e a prática pedagógica;

f) buscar e selecionar informações objetivando a construção de novos conhecimentos;

g) articular diferentes conhecimentos;

h) integrar vários softwares e mídias na realização de projetos de aprendizagem;

i) interagir e cooperar com os colegas;

j) criar e animar comunidades virtuais.

\section{Sujeitos da pesquisa: professoras-alunas}

Na primeira semana do semestre, foi feito um diagnóstico com o objetivo de compreender melhor o perfil das alunas. Para isso, foi utilizado um formulário no Google Drive no qual foram identificados alguns pontos: faixa etária, formação anterior à universidade, atuação profissional e alguns aspectos relacionados à temática da atividade acadêmica que é o "Ensino e Aprendizagem no Mundo Digital".

Do total de 31 alunas, 25 responderam o questionário, o qual nos retornou com alguns dados importantes: $65,7 \%$ tinham entre 41 e 60 anos; $63,6 \%$ acessavam a internet de casa e 33,3\% acessavam no celular também; 78,8\% acessavam diariamente; acessam a internet para: 44,8\% para encontrar amigos; $51,7 \%$ para se divertir; $48,5 \%$ para fazer pesquisas; $57,1 \%$ para fazer compras; as tecnologias mais usadas são: 97\% Word; 87,9\% Facebook; 78,8\% Moodle.

Inicialmente foram feitas perguntas mais no âmbito instrumental para de uma forma bastante objetiva analisar o quanto as alunas tinham de repertório no que se referia ao estar na rede. Com os dados pode-se perceber que a grande maioria, ou seja, quase $80 \%$ acessavam a internet diariamente com objetivos diversos, tais como lazer, relacionamentos, estudos e/ou exercer atividades do dia a dia como, por exemplo, fazer compras. Importante analisar nestes dados que as alunas fazem parte destes processos comunicativos estabelecendo o social reticular, que é

[...] expressão de uma cultura ecossistêmica nos contextos digitais dos processos comunicativos e que caracteriza as formas de uma inteligência relacional, sem centro e distribuída em todos os lugares. A ação e o conhecimento do sujeito se tornam assim relacionados e não mais autocentrados, resultado de uma qualidade conectiva que manifesta a passagem da comunicação com o ambiente à comunicação no ambiente (DI FELICE, 2012, p. 18). 
Nessa concepção, percebe-se uma estreita relação entre a perspectiva apresentada com as redes digitais. Sendo assim, há a "possibilidade de não serem apenas receptores de informação, mas também produtores, os indivíduos conectados em rede podem ultrapassar a tradicional e hierárquica dicotomia emissor-receptor" (DI FELICE, 2012b, p.52).

\section{Análise dos dados}

Ainda sobre o diagnóstico, respondido como uma das primeiras atividades no ambiente virtual, quando perguntadas sobre as práticas pedagógicas usando tecnologias, surgiram alguns relatos importantes. Uma parte apresentou ter poucas vivências e/ou temor em relação às tecnologias, mas outra parte já utilizou.

$\mathrm{O}$ que anteriormente foi apresentado por quase $80 \%$ das alunas ao relatarem que utilizam a internet para diferentes ações, o mesmo não acontece no âmbito das práticas pedagógicas, o que fica evidenciado nos seguintes relatos: "Apresento poucas vivências com os meus alunos" (Informação verbal) ${ }^{3}$.

Não quer dizer que a prática inexiste, mas afirma ser pouca. Já o relato seguinte evidencia que os alunos sabem muito sobre o digital e assume a dificuldade em unir analógico e digital, configurando-se como híbrido, ou seja, coexistência.

"Vejo que nossos alunos estão muito mais preparados que nos professores para este enfrentamento. Temos medo de ousar e ir além das aulas no papel e quadro." (Informação verbal) ${ }^{4}$

No outro relato, a aluna-professora evidencia que a aula de informática ainda é um momento separado do seu planejamento, pois conforme descrito há somente um acompanhamento, não incluindo a tecnologia como possibilidade de elaborar novas práticas. "Eu somente acompanho os alunos nas aulas de Informática...” (Informação verbal) $)^{5}$.

3 Aluna A, em depoimento durante a atividade Auto-avaliação e avaliação do Programa de Aprendizagem, em 30 jun. 2018 , na cidade de São Leopoldo.

${ }^{4}$ Aluna B, em depoimento durante a atividade Auto-avaliação e avaliação do Programa de Aprendizagem, em 30 jun. 2018 , na cidade de São Leopoldo.

5 Aluna C, em depoimento durante a atividade Auto-avaliação e avaliação do Programa de Aprendizagem, em 30 jun. 2018 , na cidade de São Leopoldo. 
O relato a seguir, narra dois diferentes momentos tanto na relação com a tecnologia, quanto ao resultado da experiência.

“Já trabalhei com séries iniciais e era obrigada a usar a 'lousa interativa' o que pra mim era uma tortura, pois nunca consegui utilizá-la sem auxílio de alguma outra colega. Na Educação Infantil trabalhei com mesa interativa e foi bem legal a experiência." (Informação verbal).

A obrigação em usar a lousa interativa não possibilitou uma fluência tecnológica para a professora, necessitando do auxílio de outra profissional. Com outra tecnologia, no caso da mesa interativa, a professora teve êxito. Importante notar o contexto da Educação Infantil onde esta tecnologia foi adotada para se trabalhar com os alunos.

A aluna a seguir traz um relato no qual evidencia alguns aspectos importantes no fazer pedagógico.

"Eu e meus alunos no Mundo Digital já utilizamos tecnologias, mesmo que na Educação Infantil. Ofereci a eles diversas vezes atividades lúdicas com o auxílio do tablet e do notebook, trazendo histórias e jogos que eram próprios para a faixa etária, emitindo sons e formas interativas.” (Informação verbal) 7 .

Importante ressaltar que a prática pedagógica já é mediada pelas tecnologias digitais, bem como o uso de diferentes equipamentos, adequando o planejamento "histórias e jogos" à faixa etária e promovendo a interatividade.

Fazendo uma comparação entre o percentual que usa as tecnologias e o percentual que as usam nas práticas pedagógicas, fica evidenciado um grande distanciamento, ou seja, as tecnologias ainda são muito usadas para fins pessoais tais como, compras, lazer, encontrar amigos etc., mas ainda não são incorporadas às práticas pedagógicas.

Como fica evidente no perfil do grupo, 65,7\% tem entre 41 e 60 anos, ou seja, em sua maioria, uma geração de imigrantes digitais, diferente da geração dos alunos que está na escola, que tem familiaridade no que diz respeito ao uso das tecnologias. Por isso, essa atividade acadêmica procurou proporcionar uma vivência no contexto da cultura digital para que as professoras-alunas pudessem experienciar e refletir sobre as linguagens, o ensino, a aprendizagem, a comunicação, as práticas pedagógicas etc., que são aspectos fundamentais para que o professor minimamente aprenda a lidar com esta geração, por meio da fluência técnico-didático-pedagógica. Para isto, adotou-se

${ }^{6}$ Aluna D, em depoimento durante a atividade Auto-avaliação e avaliação do Programa de Aprendizagem, em 30 jun. 2018 , na cidade de São Leopoldo.

7 Aluna D, em depoimento durante a atividade Auto-avaliação e avaliação do Programa de Aprendizagem, em 30 jun. 2018 , na cidade de São Leopoldo. 
a metodologia de projetos de aprendizagem, possibilitando vivencias e relacionando teoria e prática na temática da educação digital. Vale ressaltar, também, que no início do semestre conversei com outras duas professoras do curso para que pudéssemos unir três atividades acadêmicas: "Corpo e Currículo", "Matemática e Ensino" e "Aprendizagem no Mundo Digital". Sendo assim, os projetos de aprendizagem deveriam contemplar as seguintes temáticas: Corpo, Matemática e Tecnologias Digitais. Com esse desafio, as alunas desenvolveram os seguintes projetos:

\section{Quadro 1. Projetos e respectivas questões norteadoras}

\begin{tabular}{|l|l|}
\hline Título do Projeto & Questão Norteadora \\
\hline Matemática, corpo e mídias: o que há em comum? & $\begin{array}{l}\text { O que podemos encontrar de comum entre mídia, corpo } \\
\text { (movimentos) e matemática (horas)? }\end{array}$ \\
\hline Mídia, corpo e matemática... Um novo olhar! & $\begin{array}{l}\text { Como integrar corpo, matemática e tecnologia nas aulas de } \\
\text { história? }\end{array}$ \\
\hline Mídias, Corpo, Matemática e o pensar pedagógico. & $\begin{array}{l}\text { Curiosidade dos alunos sobre como as aranhas fabricam as } \\
\text { suas teias. }\end{array}$ \\
\hline Movimento e recursos digitais no ensino da Geometria & $\begin{array}{l}\text { Como o movimento e a geometria com uso dos recursos digitais } \\
\text { podem ampliar a prática docente? }\end{array}$ \\
\hline $\begin{array}{l}\text { Brincadeiras agressivas no âmbito escolar = como brincar sem } \\
\text { se machucar? }\end{array}$ & Como brincar sem se machucar? \\
\hline $\begin{array}{l}\text { Minecraft na educação uma perspectiva para além dos livros } \\
\text { didáticos }\end{array}$ & $\begin{array}{l}\text { Como fundamentar conceitos básicos de matemática envolvendo } \\
\text { as quatro operações de forma interdisciplinar utilizando os recursos } \\
\text { tecnológicos presentes no dia a dia de nossos alunos a favor das } \\
\text { aprendizagens? }\end{array}$ \\
\hline $\begin{array}{l}\text { A Integralização da Tecnologia e do Movimento no Ensino da } \\
\text { Matemática }\end{array}$ & $\begin{array}{l}\text { Como integralizar a Tecnologia e o Movimento nas aulas de } \\
\text { Matemática? }\end{array}$ \\
\hline Mídia, corpo e matemática: Redescobrindo possibilidades! & $\begin{array}{l}\text { Saber se havia um ponto comum entre essas três áreas do } \\
\text { conhecimento. }\end{array}$ \\
\hline
\end{tabular}

Fonte: elaborado pelo autor.

Nos projetos, as alunas deveriam adotar diferentes tecnologias digitais tanto na elaboração e desenvolvimento, quanto nas atividades a serem realizadas no contexto da escola. Com isso, foram utilizadas as seguintes tecnologias: Criação de sites (Simplesite, Webly), apresentação (Prezi), vídeo (Vimeo), Mapas conceituais (Cmap Tools, Text2mindmap), Formulário (Google Drive), Jogos (Minecraft), Blogs (Blogspot) etc. Com isso, foi evidenciado o hibridismo tecnológico digital. 


\section{Resultados e discussão}

A proposição dos Projetos de Aprendizagem desenvolvidos ao longo da atividade acadêmica resultou num processo de aprendizagem e produtos extremamente enriquecedores no contexto da escola. Como resultados dos projetos, foram evidenciados alguns aspectos, tanto na dimensão metodológica, quanto docente e também no que se refere à aprendizagem. $\mathrm{O}$ engajamento das alunas no processo possibilitou muitas aprendizagens, as quais detalharei a seguir.

Um primeiro aspecto foi no que se refere ao desenvolvimento dos projetos de aprendizagem. A compreensão das características que compõem esta metodologia ficou evidente por meio do aprender a lidar com o processo, com movimentos de fazer e refazer concepções, aprendizagens e ajustes. Também, por considerar o interesse dos alunos proporcionando uma aprendizagem relacionada ao contexto em que estes sujeitos estão inseridos. Outro aspecto importante dos projetos foi o uso de diferentes tecnologias digitais, configurando-se como hibridismo tecnológico digital, pois Schlemmer (2015), "são as ações e interações entre atores humanos e não humanos em espaços e culturas analógicas e digitais, constituindo-se em fenômenos indissociáveis, redes que interligam naturezas, técnicas e culturas". Assim, a apropriação das tecnologias digitais e a relação com o contexto configurou-se num híbrido tecnológico e na multimodalidade, pois as atividades online se imbricaram com as atividades presenciais no contexto da escola.

Outro aspecto importante foi a inovação das práticas pedagógicas, pois os discursos "isto não dá pra fazer", "na escola não tem equipamento", "o laboratório não pode ser usado" deram lugar a diferentes relatos:

"O projeto trabalhado gerou conflitos positivos, pois toda a aprendizagem foi construída partindo da pergunta norteadora e as dúvidas e certezas dos alunos, onde foram buscadas soluções através de pesquisas em mídia, construções de jogos didáticos e linha do tempo, representações corporais visando a integralidade educacional." (Informação verbal) ${ }^{8}$.

Conforme Di Felice (2012, p. 16) “A ação e o conhecimento do sujeito se tornam assim relacionados e não mais autocentrados, resultado de uma qualidade conectiva que manifesta a passagem da comunicação com o ambiente à comunicação no ambiente". Ou seja, todos os sujeitos envolvidos estão aprendendo e o professor torna-se um mediador do processo,

8 Aluna E, em depoimento durante a atividade Autoavaliação e avaliação do Programa de Aprendizagem, em 30 jun. 2018 , na cidade de São Leopoldo. 
"Nessa atividade compreendi melhor a importância das tecnologias em nosso trabalho e até mesmo no nosso dia a dia, e como o projeto produzido levando em conta o interesse do aluno se torna rico e produtivo. Todas essas aprendizagens levo para a vida." (Informação verbal) ${ }^{9}$

Com isso, retomo o conceito de cibercultura (LEMOS, 2004, p. 105) o qual tem como uma das suas características a liberação do pólo de emissão, o qual afirma que todo sujeito pode ser autor e compartilhar na rede suas produções.

“Consideramos que o PA atendeu o esperado, pois tornou essa aprendizagem construída pelos alunos ativa, interessante, significativa, real e atrativa, tornando o processo ensinar/aprender um trabalho agradável, sem impor os conteúdos e desenvolvendo a autonomia do aluno. Possibilitando com que ele busque informações, leia, pesquise, converse, enfim, faça investigações, formulando hipóteses, reunindo o que for necessário de informações para a solução do seu problema." (Informação verbal) ${ }^{10}$.

Segundo o relato anterior, os alunos tornam-se autores nesse processo de construção do conhecimento. Para isso, evidenciado no relato, há pesquisa, autonomia, cooperação por meio de conversas, elaborar perguntas e procurar respostas. Além disso, a questão da interdisciplinaridade que foi o desafio posto no início do semestre, gerou aprendizagens.

"Desta forma a interdisciplinaridade que envolveu as atividades acadêmicas de matemática, corpo e currículo e mídia foram desenvolvidas dentro da execução de um projeto de aprendizagem intitulado 'Corpo e Matemática... um novo olhar!' Onde o diferencial teórico teve destaque dentre as atividades proporcionando a junção teoria e prática.” (Informação vebal) ${ }^{11}$.

A avaliação geral a partir dos relatos das alunas foi bastante satisfatória, pois as professoras-alunas por meio do engajamento desencadearam uma reflexão muito significativa sobre a geração digital e as práticas pedagógicas realizadas no contexto do mundo digital. Como o espaço para a escrita é limitado, trouxe somente alguns relatos, mas, como é possível perceber, as aprendizagens geradas foram de uma grande dimensão e importância na formação destas professoras-alunas.

9 Aluna F, em depoimento durante a atividade Auto-avaliação e avaliação do Programa de Aprendizagem, em 30 jun. 2018 , na cidade de São Leopoldo.

${ }^{10}$ Aluna G, em depoimento durante a atividade Auto-avaliação e avaliação do Programa de Aprendizagem, em 30 jun. 2018 , na cidade de São Leopoldo.

${ }^{11}$ Aluna H, em depoimento durante a atividade Auto-avaliação e avaliação do Programa de Aprendizagem, em 30 jun. 2018 , na cidade de São Leopoldo. 


\section{Considerações finais}

Para iniciar esta sessão, me atrevo a nominar não como conclusão, mas sim como considerações finais. Este final diz respeito somente a esta experiência com uma turma de professoras-alunas do curso de Pedagogia Parfor, as quais já têm muita experiência na docência, mas se abriram para vivenciar e aprender novas possibilidades de ensinar. Por isso, quero retomar a pergunta inicial deste relato de experiência profissional: compreender de que forma as alunas do curso de Pedagogia Parfor se apropriam das tecnologias digitais por meio do engajamento e do desenvolvimento de projetos de aprendizagem na perspectiva do hibridismo e da multimodalidade proporcionando a reinvenção da sua prática docente?

Para responder essa questão, depois da retomada da teoria, do processo vivenciado pela turma e dos relatos colhidos, ouso afirmar que houve uma quebra de paradigma, pois as certezas tornaram-se provisórias e dúvidas foram criadas, mas como temporárias. Assim, o questionamento moveu o grupo na elaboração de diferentes projetos, adoção de diferentes tecnologias e crescentes aprendizagens.

As atividades desenvolvidas no contexto da universidade, por meio da formação inicial, estiveram todo o tempo conectadas com a escola, que era o ambiente onde as professoras-alunas estavam atuando. Com isso, muitos foram os desdobramentos em diferentes contextos, com diferentes sujeitos e em diversos níveis, seja no berçário, na educação infantil ou no ensino fundamental.

Para finalizar, o engajamento e o desenvolvimento dos projetos no contexto do hibridismo e da multimodalidade proporcionaram transcender o espaço da sala de aula, pois as quatro paredes deram lugar a diferentes experiências não pelo simples fato de serem diferentes, mas tiveram como único foco a aprendizagem dos alunos. Usos de diferentes tecnologias digitais e muitas atividades analógicas evidenciaram a coexistência datas duas dimensões.

\section{Referências}

BACKES, L.; SCHLEMMER, E. Práticas pedagógicas na perspectiva do hibridismo tecnológico digital. Revista Diálogo

Educacional, Curitiba, v. 13, n. 38, jan./abr. 2013, p. 243-266. https://doi.org/10.7213/dialogo.educ.7644

DI FELICE, M. Redes Sociais Digitais, epistemologias reticulares e a crise do antropomorfismo social. Revista USP, v. 22, p. 06-19, 2012a. https://doi.org/10.11606/issn.2316-9036.v0i92p6-19

DI FELICE, M.; TORRES, J. C.; YANAZE, L. K. H. Redes digitais e sustentabilidade - as interações com o meio ambiente na era da informação. São Paulo: Annablume, 2012b. v. 1. 
FAGUNDES, L. C.; SATO, L. S.; MAÇADA, D. L. Projeto? O que é? Como se faz? In: FAGUNDES, L. C.; SATO, L. S.; MAÇADA, D. L. Aprendizes do Futuro: as inovações começaram! Brasília, MEC, 1999. (Coleção Informática para a mudança na Educação). Disponível em: http://mathematikos.psico.ufrgs.br/textos.html. Acesso em: 2 nov. 2019. https://doi.org/10.22456/19821654.6240

LATOUR, B. Cogitamus: seis cartas sobre as humanidades científicas. Rio de Janeiro: Editora 34, 2016.

LEMOS, A. Cibercultura, tecnologia e vida social na cultura contemporânea. 2. ed. Porto Alegre: Sulina, 2004.

LEMOS, A. O que é Cibercultura. 2010. (5min54s). Disponível em: https://www.youtube.com/watch?v=hCFXsKeIs0w. Acesso em: 23 maio 2016.

MINAYO, M. C. de S. O desafio da pesquisa social. In: MINAYO, M. C. de S. (org.). Pesquisa Social: teoria, método e criatividade. 26. ed. Petrópolis, RJ: Vozes, 2007.

MORAES, R. Uma tempestade de luz: a compreensão possibilitada pela análise textual discursiva. Ciência \& Educação, Bauru, v.9, n. 2, p. 191-211, 2003. https://doi.org/10.1590/s1516-73132003000200004

SCHLEMMER, E. Mídia social em contexto de hibridismo e multimodalidade: o percurso da experiência na formação de mestres e doutores. Revista Diálogo Educacional, Curitiba, v. 15, n. 45, p. 399-421, maio/ago. 2015. https://doi.org/10.7213/dialogo. educ.15.045.ds02

SILVA, E.L.; MENEZES, E. M. Metodologia da pesquisa e elaboração de dissertação. 3. ed. Florianópolis: Laboratório de Ensino a Distância da UFSC, 2001.

Recebido em: 30/7/2018.

Aprovado em: 12/12/2018

Publicado em: 31/12/2019.

\section{Endereço para correspondência:}

Ederson Luiz Locatelli

Rua Guilherme Alves, 1131/605 - Petrópolis

90680-001, Porto Alegre, RS, Brasil

\section{Autor:}

EDERSON LUIZ LOCATELLI

Universidade do Vale do Rio dos Sinos.

Orcid: https://orcid.org/0000-0002-3244-6600

E-mail: locatelli1501@gmail.com 